\title{
Radioprotective potential of Costus afer against the radiation- induced hematological and histopathological damage in mice
}

\author{
Idowu Richard Akomolafe, Naven Chetty \\ Discipline of Physics, School of Chemistry and Physics, University of KwaZulu-Natal, Pietermaritzburg, South Africa
}

Received: January 4, 2021

Revised: February 19, 2021

Accepted: February 25, 2021

Correspondence:

Naven Chetty

Discipline of Physics, School of

Chemistry and Physics, University of

KwaZulu-Natal, Private Bag X01,

Scottsville, 3209, Pietermaritzburg,

South Africa.

Tel: +27-332605660

E-mail: chettyn3@ukzn.ac.za

ORCID:

https://orcid.org/0000-0002-0916-578X
Purpose: This study investigated the possible radioprotective effect of Costus afer extract (CAE) on hematological and histopathological parameters of mice.

Materials and Methods: Fifty-four male mice with mass between 37-43 g, 11-13 weeks old were used for this study. We divided the mice into six different groups containing nine animals, which were then further sub-divided into irradiated groups and un-irradiated groups. Animals received $250 \mathrm{mg} /$ $\mathrm{kg}$ body weight extract of CAE by oral gavage for 6 days in addition to feeding and water ad libitum. Animals in the irradiated group were exposed to radiation at the Department of Radiotherapy and Oncology, Grey's Hospital using a linear accelerator. Blood samples were collected at 48-hour post-irradiation for the hematology test followed by histopathology examination of kidney and liver.

Results: Our findings revealed that $3 \mathrm{~Gy}$ and 6 Gy dose of X-ray radiation caused a significant reduction in the white blood cell, packed cell volume, hemoglobin, neutrophils, lymphocytes, eosinophils, and platelet counts compared with the control group. However, the administration of CAE before irradiation significantly increased the mentioned parameters. There was no increase in red blood cell and monocyte among treated groups compared with the control. Histopathological changes in the kidney and liver sections revealed that no visible lesion in the pretreated mice. Hepatocytes seem to be within normal histological limits.

Conclusions: This study concludes that CAE offered some protection against radiation-induced hematological alterations, but there was no significant improvement in the histopathological parameters. Thus, further studies are needed to validate its radioprotective effect on histopathological variables.

Keywords: Radiation protection, Pathology, Radiotherapy, Linear accelerator, Hematology, Cancer

\section{Introduction}

The usage of ionizing radiation for medical purposes has increased significantly over the last few decades, which has increased cancer risk associated with this increased utilization of ionizing radiation [1]. Radiation exposure can cause measurable injuries to the hematopoietic, gastrointestinal and central nervous systems, contingent on radiation exposure doses [2]. This exposure can also lead to water's radiolysis, which produces reactive oxygen species like free radical and hydroxyl ions. Due to the presence of unpaired elec- trons, free radicals are very active. They can damage biological molecules such as the deoxyribonucleic acid (DNA), protein and membrane lipids, resulting in biologic and cellular damage [2,3]. In assessing the degree of radiation exposure to the body, changes in blood values have been established as being an advantage. The hematopoietic system, consisting of bone marrow and lymph tissues, has been described as the body's most radiosensitive organ [4]. Two modes of treatment for cancer are predominant aside from surgery. The first is chemotherapy, which used cytostatic drugs. Radiotherapy is the other. Radiotherapy is the medical use of ionizing radia- 
tion in cancerous cells' treatment $[5,6]$. However, one significant challenge in cancer cells' radiotherapy is the exposure of surrounding tissues to undesirable radiation doses, leading to biological damage [5]. The need to develop drugs that can reduce the deleterious and harmful effect of radiation and perform reproductive functions becomes vital.

The year 1948 marked the hallmark in the discovery of a compound that offers protection against radiation. The discovery aroused the US Army's interest, and the compound discovered then was cysteine [7]. Patt et al. [8] were the pioneer researchers to examine the protective effect of amino-acid cysteine in mice and rats exposed to lethal radiation doses. The report revealed cysteine's potential to enhance mice and rats' survival against radiation-induced lethality [9]. However, it was discovered that cysteine, as a radioprotector posed severe challenges, as it was toxic and caused nausea and vomiting at the level of the dose required for protection [10]. The need to reduce the toxicity level led to further development program initiated in 1959 by the US Army and conducted at the Walter Reed Institute of Research. During this time, more than 4,000 compounds were synthesised and tested. One of the active compounds discovered during the same study was WR-2721, also known as amifostine [6]. To date, it remains the most reliable of those synthesised in the Walter Reed series [11], and amifostine is the only radioprotective drug approved by the US Food and Drug Administration (FDA) for use in radiation treatment [6]. Although amifostine was the only radioprotector drug approved by FDA against radiation, for thwarting xerostomia in patients treated for head and necked cancer, there remains its cumulative toxicity on daily administration with radiotherapy, which was revealed in sneezing, allergic reactions, somnolence, hypotension, and nausea $[6,11]$. Thus, an urgent need to find an alternative natural substance with similar characteristics to the synthetic compound can offer protection against radiation while remaining non-toxic, effective, available and affordable. A few of the plants extract which have been found to provide a protective measure against the radiation-induced damaged in mammals include Mentha arvensis, Syzygium cumini, Liv-52, Nardostachys jatamansi, Ocimum sanctum, Aegle marmelos (L.), Zinger officinale, Tragia involucrata, grape seed, nanocurcumin [7,12-16].

Costus afer belongs to the family of Zingiberaceae otherwise called Costaceae; it is a relatively tall permanent herbaceous, branchless herbal plant with crawling rhizome. It is predominantly grown in the thick forest and riverbanks of tropical West Africa [17]. Costus afer is often called a bush cane or ginger lily and has a variety of names in Nigeria such as "Okpete" in the Southeast, "Kakizawa" in the Northern area, "ireke-omode" in the Southwest, "Ogbodou" in the Niger Delta, and "Mbritem" in the Southern re- gion [17]. In Cameroon, it is referred to as "Monkey sugar cane" [17]. It has been reported that the stem, seeds and rhizomes of Costus afer contain numerous bioactive metabolites [18]. A report from Soladoye and Oyesika [19] on Costus afer indicates that the plant is highly regarded for anti-inflammatory, anti-diabetic, and anti-arthritic features in the Southeast and Southwest region. It is widely used as a medicinal herb, most notably its seeds, stem, leaf, and rhizomes harvested from the wild $[17,20]$.

The present study aimed to investigate the possible radioprotective efficacy of the Costus afer plant against whole-body radiation-induced hematological and histopathological disorder in mice exposed to double doses of $\mathrm{X}$-ray radiation based on reported folklore medicine use.

\section{Materials and Methods}

\section{Plant collection, identification and extract preparation} The rhizome, stem, and leaves of Costus afer were harvested from uncultivated farmland at Ikole-Ekiti in Ekiti State, South-west, Nigeria, in December 2019. A Botanist (Mr Esinekhuai Donatus) at the Herbarium, Department of the Botany, University of Ibadan, Nigeria, where voucher specimen number UIH-22932 was deposited, made the botanical identification and authentication of the plant. The leaf, stem and rhizome were hand-searched mechanically to ensure they were pest-free. They were also rinsed with tap water and air-dried for a few days at room temperature. After that, they were pulverised at the Biomedical Research Laboratory, School of Chemistry \& Physics, University of KwaZulu-Natal (UKZN), Pietermaritzburg campus, with an electric grinder to provide enough surface area for maceration to occur. The powder material (638.03 g) of Costus afer was macerated in $3.75 \mathrm{~L}$ of high quality $(99.9 \%$ pure) methanol for 72 hours at room temperature. The macerated solution was shaken intermittently to ensure thorough mixing. The maceration was done two different times. The combined extract was filtered using a Whatman No. 1 filter paper under vacuum filtration. The obtained filtrate was concentrated and evaporated using a rotary evaporator to remove all traces of methanol. An approximate $4.5 \%$ yield of the extract obtained was placed in an airtight container and stored in a refrigerator at $4{ }^{\circ} \mathrm{C}$ until the time of use.

\section{Animal care and selection}

Fifty-four male BALB/c mice of mass between $37-43 \mathrm{~g}, 11-13$ weeks old were used for this study. The animals were inbred the Animal House of the School of Life Sciences, University of KwaZulu-Natal Pietermaritzburg campus. The University of KwaZulu-Natal Animal Research Ethics Committee (UKZN, AREC) approved the 
research protocol used in this study with a protocol reference number AREC/026/019D. Moreover, all our procedures conformed to the National Institute of Health guidelines for laboratory animal care and used in biomedical research [21]. Throughout the study, they were kept in the animal house, maintained under a strictly controlled temperature of between $23^{\circ} \mathrm{C}-25^{\circ} \mathrm{C}$, with 12 -hour light and dark cycle and were given free access to a standard diet and clean water ad libitum. The experimental animals were humanely handled and kept inside clean well-ventilated transparent plastic-type IV cages with wood shavings and naturally illuminated animal room. Behavioural enrichment in the mouse cages in the form of egg boxes and shredded paper were provided. The mice were allowed some days to acclimatise to animal room conditions before treatment commenced. All animals were examined, and clinical signs were recorded daily before and after dosing during the treatment period. The mass of the animals was also recorded.

\section{Acute toxicity study}

Twenty male mice were used for the toxicity test. The mice were divided into four groups of five animals in each group. The acute toxicity test of Costus afer extract was determined over a 14-day observation period. CAE was administered by oral gavage at doses of $100 \mathrm{mg} / \mathrm{kg}, 200 \mathrm{mg} / \mathrm{kg}, 300 \mathrm{mg} / \mathrm{kg}$, and $400 \mathrm{mg} / \mathrm{kg}$ body weight. The mice were observed for 14 days for signs of acute toxicity and death [22]. CAE's oral administration to mice did not produce death or toxic effect in the treated groups during the 14 days observation period. The median dose $(250 \mathrm{mg} / \mathrm{kg})$ was chosen and used for further studies in the present work.

\section{Administration of extracts}

Fifty-four male BALB/c mice were used for the experiment. The mice were randomly divided into six groups, with nine animals in each group. The grouping and treatment of animals are presented in Table 1. Animals in the group code CAE, CAE-3Gy and CAE-6Gy received $250 \mathrm{mg} / \mathrm{kg}$ body weight of extract of Costus afer by oral gavage for 6 days before radiation exposure.

Table 1. Treatment of animals for Costus afer extract

\begin{tabular}{ll}
\hline Group code & \multicolumn{1}{c}{ Treatment } \\
\hline CNT & $\begin{array}{c}\text { Control (un-irradiated) } \\
\text { Animals treated with } 250 \mathrm{mg} / \mathrm{kg} \text { body weight only } \\
\text { (un-irradiated) }\end{array}$ \\
IR_3Gy & $\begin{array}{l}\text { Irradiated (3 Gy) animals only } \\
\text { IR_6Gy }\end{array}$ \\
Irradiated (6 Gy) animals only \\
CAE_3Gy & $\begin{array}{c}\text { Irradiated (3 Gy) animals treated with } 250 \mathrm{mg} / \mathrm{kg} \text { body } \\
\text { weight }\end{array}$ \\
CAE_6Gy & $\begin{array}{c}\text { Irradiated (6 Gy) animals treated with } 250 \mathrm{mg} / \mathrm{kg} \text { body } \\
\text { weight }\end{array}$ \\
\hline
\end{tabular}

CNT, control; $\mathrm{CAE}$, Costus afer extract; IR, ionizing radiation.

\section{Procedure for irradiation}

An hour after the last administration of the extract, the mice were exposed to X-ray radiation at the Department of Radiotherapy and Oncology, Grey's Hospital, Pietermaritzburg, South Africa. A Linear Accelerator (LINAC) manufactured by Varian (model: Clinac 2100C) serves as the radiation source. The LINAC uses electricity to produce energy beams of X-rays and beams of electrons usually collimated to treat cancer patients. Nine animals packed inside a specially designed transparent plastic cage and their movement restrained during the irradiation process. A total of 36 mice (excluding animals in group CNT \& CAE) were exposed to 6-MV photons from LINAC, and the irradiated groups were exposed to whole-body low energy X-ray radiation dose of $300 \mathrm{cGy}$ and $600 \mathrm{cGy}$ at a dose rate of 400 $\mathrm{MU} / \mathrm{min}$ under a standard condition of 100 monitor units $(\mathrm{MU})=1$ Gy. A source to the surface distance of $90 \mathrm{~cm}$ at a depth of $10 \mathrm{~cm}$ was used for the irradiation, while a field size of $40 \mathrm{~cm} \times 24 \mathrm{~cm}$ was found suitable for the irradiation process. After the radiation exposure, the mice were put into their cages and transferred back to the animal house.

\section{Body mass and relative organ mass}

The animals' body mass was recorded on the day they were randomised into different groups, and every day during the pretreatment process. These served as the initial masses. Two mice from each group were euthanised by cervical dislocation 48 hours after irradiation, the visceral organs (kidney and liver) of the mice were surgically removed, rinsed in 0.9\% normal saline, blotted with filter paper, weighed, and the relative organ mass was calculated and expressed as a percentage of the body mass.

Relative organ mass $=\frac{\text { Absolute organ mass }(g)}{\text { Body mass of mouse on the day of sacrifice }(g)} \times 100$

\section{Determination of hematological parameters}

Forty-eight hours after the irradiation, all the animals were euthanised by cervical dislocation, and blood samples were collected from them. The blood collection was done from the posterior vena cava of the heart using a 23-gauge needle and a 1-mL syringe into ethylenediaminetetraacetic acid (EDTA) bottles with anticoagulant for hematological analysis. The packed cell volume (PCV), hemoglobin $(\mathrm{Hb})$, red blood cell $(\mathrm{RBC})$, total white blood cell count (WBC), neutrophils, lymphocytes, monocytes, eosinophils, platelet count values were determined using the Sysmex XE-2100 Haematology Automated Analyser machine.

\section{Histopathology examination}

Shortly after collecting blood samples on 48-hour post-irradiation, 
two mice were taken from the euthanised animals, and their visceral organs (kidney and liver) were harvested. The mass of the fresh livers and both kidneys were determined (measured in grams) after which they were fixed in 10\% buffered formalin. Two hours post-immersion in formalin, the tissues were dehydrated in an ascending grade of ethanol, cleared in xylene and embedded in paraffin wax. Serial sections of 4- $\mu \mathrm{m}$ thick were obtained on glass slides using a rotary microtome. The deparaffinized sections were stained routinely with hematoxylin and eosin (H\&E) and mounted. All sections were examined with a standard light microscope (Olympus, Tokyo, Japan) and scanned digitally by an Aperio C52 (Leica Biosystems, Heidelberg, Germany). Images and sections were evaluated under $\times 10, \times 20$, and $\times 40$ magnification. Images were taken from the digitally scanned slides with ImageScope Software (Leica) and stored as jpeg image files.

\section{Statistical analysis}

The hematological parameters were analysed by one-way analysis of variance (ANOVA), followed by Tukey's multiple comparison test in which all the treatment groups were compared with the control group. SPSS statistical package version 20.0 (IBM, Armonk, NY, USA) was used for the analysis. Results are reported as mean \pm SEM (standard error of the mean) and $p<0.05$ were considered significant values.

\section{Results}

\section{Effect of extract on relative organ mass}

Exposure of animals to radiation can cause a reduction in food intake, which may lower the immune system, thereby causing changes in the body weight of the exposed living animals. Moreover, these changes depend on the types of radiation, the dose of radiation and post-irradiation time (latent period). In this investigation, the mean relative organ mass of the kidneys in the control group (CNT) was $1.13 \pm 0.04$ as compared with the mean relative organ mass in the irradiated groups (IR_3Gy and IR_6Gy) of $0.76 \pm 0.01$ and $0.93 \pm 0.04$, respectively. Our results revealed that radiation significantly ( $p<0.05$ ) decreased the relative organ mass of the kidney of the irradiated groups when compared with the un-irradiated group (control). However, there was no significant alteration in the pretreatment groups' relative organ mass (CAE_3Gy and CAE_6Gy) compared with the irradiated groups only (Table 2). The mean relative organ mass in the treatment groups (CAE_3Gy and CAE_6Gy) were $0.80 \pm 0.07$ and $0.89 \pm 0.05$, respectively. The relative organ mass of the irradiated groups' kidneys decreased compared with the control, but there was no significant improvement in the pretreatment groups. The levels of radiation-induced damage observed in the pretreatment groups' kidney did not cause noticeable changes in their relative organ mass, probably due to the short period between exposure and the time the organs were harvested. Similar results were observed in the liver analysis. The mean relative organ mass of the liver in the control group was $6.71 \pm 0.08$. At the same time, the mean relative organ mass for the irradiated groups was $5.50 \pm 0.04$ and $4.88 \pm 0.05$ for group IR_3Gy and IR_6Gy, respectively. There was no significant increase in the relative organ mass of the pretreatment groups.

\section{Effect of extract on hematological parameters}

\section{1) red blood cell}

Table 3 shows a significant $(\mathrm{p}<0.05)$ decrease in the mean value of RBCs of the irradiated groups (IR_3Gy \& IR_6Gy) when compared with the control (CNT). Moreover, there was significant difference ( $p<0.05$ ) in the erythrocyte value of CAE group when compared with the control (CNT). However, the pretreatment of mice in groups (CAE_3Gy and CAE_6Gy) with the extract did not improve the blood parameter, as there was no significant increase in the red blood count of the pretreatment groups.

\section{2) Packed cell volume}

Table 3 shows a significant $(p<0.05)$ reduction of the mean of PCV of mice in groups (IR_3Gy and IR_6Gy) when compared with the control (CNT) at 48-hour post-irradiation. Also, a significant reduction $(p<0.05)$ in PCV of mice in the CAE group was observed compared with the control (CNT). The mean of PCV of mice in the group IR_6Gy was seen to be slightly less than the mean value of group IR_3Gy; this shows the damaging effect of ionizing radiation at a higher dose. In the pretreatment groups (CAE_3Gy and CAE_6Gy), the administration of the extract before exposure ameliorated the disorder caused by $\mathrm{X}$-ray radiation by significantly increasing the mean of PCV when compared with groups (IR_3Gy and IR_6Gy).

Table 2. Effect of extract on the relative organ mass

\begin{tabular}{lcc}
\hline Code & Kidneys & Liver \\
\hline CNT & $1.13 \pm 0.04$ & $6.71 \pm 0.08$ \\
CAE & $0.89 \pm 0.05$ & $5.10 \pm 0.18$ \\
IR_3Gy & $0.76 \pm 0.01$ & $5.50 \pm 0.04$ \\
IR_6Gy & $0.93 \pm 0.04$ & $4.88 \pm 0.05$ \\
CAE_3Gy & $0.80 \pm 0.07$ & $5.46 \pm 0.04$ \\
CAE_6Gy & $0.89 \pm 0.05$ & $4.19 \pm 0.32$ \\
\hline
\end{tabular}

Values are presented as mean \pm standard deviation $(n=2)$.

$\mathrm{CNT}$, control; CAE, Costus afer extract; IR, ionizing radiation. 
Table 3. Effect of methanol extract of Costus afer and X-ray radiation on the RBC, PCV, hemoglobin, WBC, and neutrophils of mice

\begin{tabular}{lccccc}
\hline Group code & $\mathrm{RBC}\left(\times 10^{12} / \mathrm{L}\right)$ & $\mathrm{PCV}(\mathrm{L})$ & $\mathrm{Hb}(\mathrm{g} / \mathrm{dL})$ & $\mathrm{WBC}\left(\times 10^{9} / \mathrm{L}\right)$ & $\mathrm{Neutrophils}\left(\times 10^{9} / \mathrm{L}\right)$ \\
\hline CNT & $11.05 \pm 0.58$ & $57.20 \pm 2.06$ & $17.46 \pm 0.12$ & $9.22 \pm 0.10$ & $7.63 \pm 0.31$ \\
CAE & $9.94 \pm 0.35^{*}$ & $47.47 \pm 3.70^{*}$ & $16.38 \pm 0.22^{*}$ & $7.60 \pm 0.21^{*}$ & $5.16 \pm 0.41^{*}$ \\
IR_3Gy & $9.41 \pm 0.38^{*}$ & $33.96 \pm 0.22^{*}$ & $13.60 \pm 0.13^{*}$ & $2.54 \pm 0.11^{*}$ & $5.43 \pm 0.37^{*}$ \\
IR_6Gy & $8.99 \pm 0.47^{*}$ & $33.23 \pm 1.09^{*}$ & $12.20 \pm 0.21^{*}$ & $1.26 \pm 0.13^{*}$ & $2.74 \pm 0.43^{*}$ \\
CAE_3Gy & $9.69 \pm 0.58$ & $41.10 \pm 1.09^{* *}$ & $14.64 \pm 0.27^{* *}$ & $3.38 \pm 0.33^{* *}$ & $5.20 \pm 0.35$ \\
CAE_6Gy & $9.61 \pm 0.18$ & $41.83 \pm 0.82^{* *}$ & $14.56 \pm 0.39^{* *}$ & $2.95 \pm 0.38^{* *}$ & $6.38 \pm 1.04^{* *}$ \\
\hline
\end{tabular}

Values are presented as mean \pm standard error of mean $(n=9)$.

CNT, control; CAE, Costus afer extract; IR, ionizing radiation; RBC, red blood cell; PCV, packed cell volume; WBC, white blood cell.

${ }^{*} p<0.05$ versus CNT, ${ }^{* *} p<0.05$ versus IR_3Gy \& IR_6Gy. Values along the same column with different superscripts are significantly different at $5 \%$ $(p<0.05)$ level.

\section{3) Hemoglobin}

There was a slight reduction in the mean value of $\mathrm{Hb}$ of mice in the irradiated groups (IR_3Gy and IR_6Gy) when compared with the control (CNT) and a significant decrease $(p<0.05)$ in the $\mathrm{Hb}$ of mice in CAE group was recorded when compared with the control (CNT) (Table 3). However, the treatment of mice with the extract before exposure seemed to have a slight increase in the mean of $\mathrm{Hb}$ of the group CAE_3Gy and group CAE_6Gy at a significant level $(p<0.05)$ when compared with the irradiated groups (IR_3Gy and IR_6Gy).

\section{4) White blood cell}

lonizing radiation caused a significant reduction $(p<0.05)$ in the mean of WBC in groups IR_3Gy and IR_6Gy when compared to the control (CNT). Similarly, the mice that received extract only (CAE group) showed a significant reduction $(p<0.05)$ in their WBC when compared with the control (CNT). The alterations in the WBC of mice among the treatment groups (CAE_3Gy and CAE_6Gy) were significantly increased compared with the control (CNT) (Table 3).

\section{5) Neutrophils count}

Table 3 shows a significant reduction $(p<0.05)$ in the mean of the irradiated groups' mean neutrophils compared with the control (CNT). Moreover, a significant reduction $(p<0.05)$ in the neutrophil of mice in the CAE group was observed when compared with the control (CNT). The treatment of mice with CAE did not statistically increase the mean of neutrophil in the group CAE_3Gy, whereas, there was a significant improvement in the group CAE_6Gy compared with group IR_6Gy.

\section{6) Lymphocytes count}

In Table 4, ionizing radiation caused a significant decrease ( $\mathrm{p}<$ 0.05) of the mean of the lymphocyte count in the irradiated groups compared with the control (CNT). Similarly, a significant reduction $(p<0.05)$ in the lymphocyte of mice in the CAE group was discovered when compared with the control (CNT). However, the treat- ment of mice with the extract significantly improved the lymphocyte count in the group CAE_6Gy. There was no significant improvement in the lymphocyte count for group $C A E$ _3Gy relative to group IR_3Gy.

\section{7) Monocytes}

Table 4 shows a non-significant ( $p>0.05$ ) reduction in the monocyte count of both the irradiated groups alone compared with the control (CNT). Whereas, a slight significant increase $(p<0.05)$ in the monocyte of mice in the CAE group was observed when compared with the control (CNT). The CAE administration did not offer protection against the damaging effect of X-ray radiation on the pretreatment groups' monocyte count, as these groups show a non-significant increase in their mean value compared with groups IR_3Gy and IR_6Gy.

\section{8) Eosinophils}

Table 4 shows a slight reduction in the mean eosinophils count of the groups IR_3Gy and IR_6Gy caused by radiation, which was significant compared with the control (CNT). Also, a significant reduction $(p<0.05)$ in the eosinophil of mice in the CAE group when compared with the control (CNT) was discovered. The slight increase in pretreatment group CAE_6Gy was significant ( $p<0.05$ ) compared with group IR_6Gy, that of group CAE_3Gy was not significant relative to group IR_3Gy.

\section{9) Platelet}

The significant reduction of platelet count caused by ionizing radiation is shown in Table 4. The irradiated groups (IR_3Gy and IR_6Gy) revealed a statistically significant decrease $(p<0.05)$ in the platelet count compared with the control (CNT). Similarly, the mice in the CAE group had a significant reduction $(p<0.05)$ in their platelet count when compared with the control (CNT). There was an improvement in the pretreatment groups (CAE_3Gy and CAE_6Gy) as evidence in an increase in platelet count compared with the irradi- 
Table 4. Effect of methanol extract of Costus afer and X-ray radiation on lymphocytes, monocytes, eosinophils, and platelet of mice

\begin{tabular}{lcccc}
\hline Code & Lymphocytes $\left(\times 10^{9} / \mathrm{L}\right)$ & Monocytes $\left(\times 10^{9} / \mathrm{L}\right)$ & Eosinophils $\left(\times 10^{9} / \mathrm{L}\right)$ & Platelet $\left(\times 10^{9} / \mathrm{L}\right)$ \\
\hline CNT & $4.94 \pm 0.13$ & $2.53 \pm 0.03$ & $3.60 \pm 0.15$ & $3,401.00 \pm 45.36$ \\
CAE & $3.66 \pm 0.37^{*}$ & $3.52 \pm 0.04$ & $2.80 \pm 0.21^{*}$ & $1,355.80 \pm 254.74^{*}$ \\
IR_3Gy & $3.58 \pm 0.21^{*}$ & $2.18 \pm 0.02$ & $2.20 \pm 0.03^{*}$ & $551.60 \pm 5.91^{*}$ \\
IR_6Gy & $1.29 \pm 0.10^{*}$ & $1.84 \pm 0.04^{*}$ & $1.60 \pm 0.13^{*}$ & $340.40 \pm 35.49^{*}$ \\
CAE_3Gy & $2.01 \pm 0.24$ & $2.10 \pm 0.07$ & $2.60 \pm 0.05$ & $1,272.00 \pm 197.43^{* *}$ \\
CAE_6Gy & $2.33 \pm 0.19^{* *}$ & $1.80 \pm 0.03$ & $2.80 \pm 0.10^{* *}$ & $471.20 \pm 40.13^{* *}$ \\
\hline
\end{tabular}

Values are presented as mean \pm standard error of mean $(n=9)$.

CNT, control; $C A E$, Costus afer extract; $I R$, ionizing radiation.

${ }^{*} p<0.05$ versus CNT, ** $p<0.05$ versus IR_3Gy \& IR_6Gy. Values along the same column with different superscripts are significantly different at 5\% $(p<0.05)$ level.
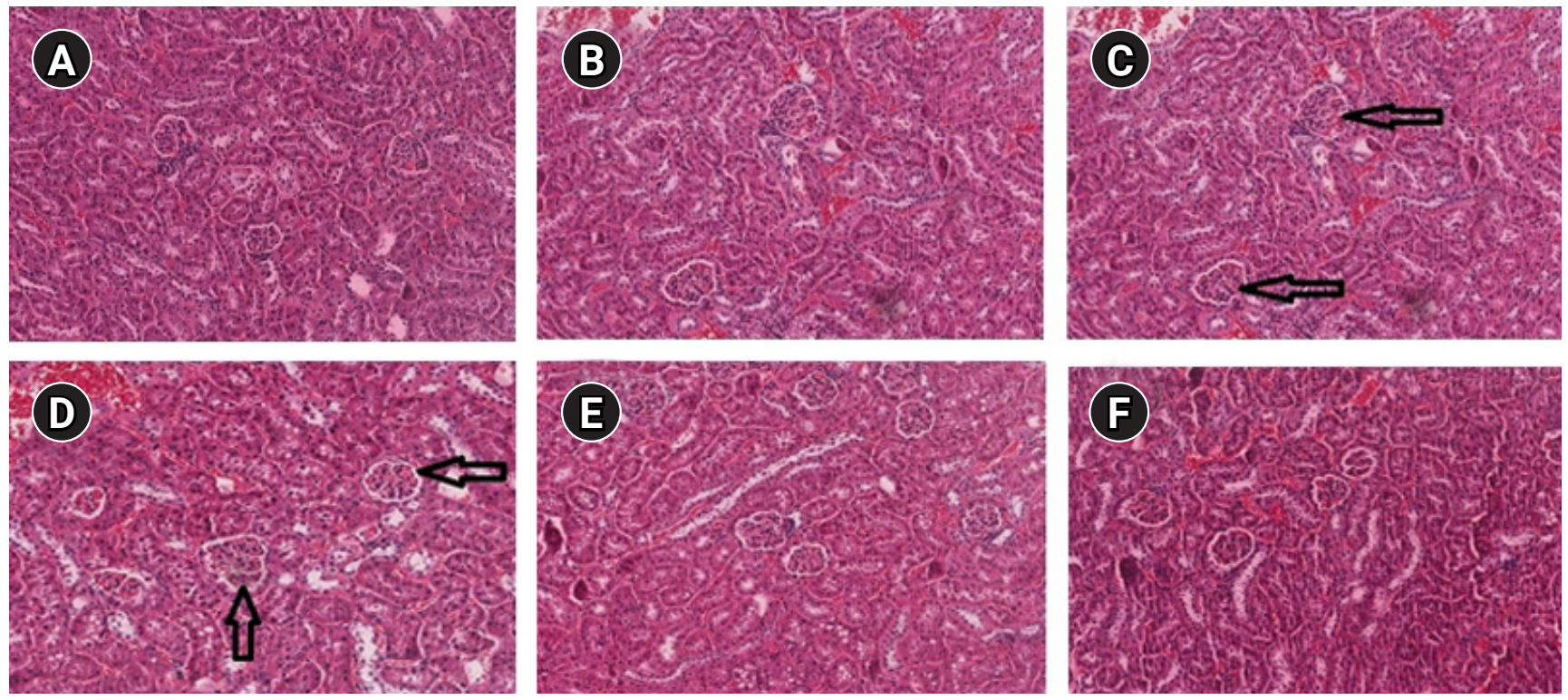

Fig. 1. Effects of Costus afer and X-ray radiation on the histological parameters of mice: the pathological analysis results of the kidney. (A) Light micrograph of the kidney section of the control mice (group CNT), the renal architecture seem intact with a normal cortex (H\&E, $\times 400)$. (B) Light micrograph of the kidney section of mice treated with Costus afer extract (group CAE) showing a normal cortex and few foci of mild sloughing off tubular epithelial cells $\left(H \& E_{1} \times 400\right)$. (C) Light micrograph of the kidney section of mice exposed to 3 Gy of X-ray showing a few foci of mild cloudy swelling of the epithelial cells (arrows) ( $\left.H \& E_{1} \times 400\right)$. (D) Light micrograph of the kidney section of mice exposed to $6 \mathrm{~Gy}$ of $X$-ray showing a few foci of moderate cloudy swelling of the epithelial cells (arrows) (H\&E, $\times 400)$. (E) Light micrograph of the kidney section of mice treated with CAE \& exposed to $3 \mathrm{~Gy}$ of $\mathrm{X}$-ray showing no visible lesion ( $\mathrm{H} \& \mathrm{E}, \times 400)$. (F) Light micrograph of the kidney section of mice treated with CAE \& exposed to $6 \mathrm{~Gy}$ of $\mathrm{X}$-ray showing no visible lesion (H\&E, $\times 400)$. CNT, control; CAE, Costus afer extract; H\&E, hematoxylin and eosin staining.

ated groups (IR_3Gy and IR_6Gy).

\section{Effect of extract on histology kidney and liver of mice after exposure to $\mathrm{X}$-ray radiation}

The histopathological examination of kidney and liver sections stained with H\&E showed that X-ray radiation-induced changes in mice's kidney and liver renal architecture in a dose-dependent manner. Fig. 1 presents the pathological analysis results of the kidney in various groups studied. Group CNT mice (control group) showed that sections from both left and right kidneys examined the renal architecture seem intact with a normal cortex and me- dulla in which normal convoluted tubules and tubular epithelial cells, glomeruli, blood vessels and stromal tissues are seen (Fig. 1A). Meanwhile, the kidney section of mice pretreated with the extract alone (group CAE) showed a normal cortex and few foci of mild sloughing off tubular epithelial cells (Fig. 1B). The mice exposed to 3 Gy and 6 Gy of X-ray radiation, group IR_3Gy and IR_6Gy, respectively, showed few foci of mild cloudy swelling of the epithelial cells tubules moderate flattening of epithelial cells in the cortex-medullary junction (Fig. 1C, 1D). The mice in the groups (CAE_3Gy and CAE_6Gy) pretreated with extract before exposure to $X$-ray radiation of $3 \mathrm{~Gy}$ and $6 \mathrm{~Gy}$ showed no visible lesion. The renal architecture 
seems intact with a normal cortex and medulla in which normal convoluted tubules and tubular epithelial cells, glomeruli, blood vessels and stromal tissues are seen (Fig. 1E, 1F).

The pathological analysis of the liver of mice in the group CNT (control) and group CAE (mice received extract only) revealed that a normal hepatic architecture is evident with a typical ratio of portal triads and hepatic lobules. No congestion is seen in the hepatic sinusoids. Hepatocytes seem to be within normal histological limits and no evidence of adhesion and inflammation (Fig. 2A, 2B). The liver histology of the mice exposed to 3 Gy and 6 Gy showed that there are random foci of mild single-cell hepatocellular necrosis. Moderate congestion is seen in the hepatic sinusoids (Fig. 2C, 2D). Group CAE_3Gy mice (mice pretreated with extract followed by 3 Gy) showed foci of mild random single hepatocellular necrosis. Hepatocytes seem to be within normal histological limits. The mice in the group CAE_6Gy (mice pretreated with extract followed by 6 Gy) showed a normal hepatic architecture that is evident with a typical ratio of portal triads and hepatic lobules. Mild congestion is seen in the hepatic sinusoids. Hepatocytes seem to be within normal histological limits (Fig. 2E, 2F).

\section{Discussion and Conclusion}

Exposure of humans to ionizing radiation can cause the production of free radicals and reactive oxygen species (ROS) which are capable of damaging the DNA, protein and membrane lipids, thus resulting in biological and cellular damages [23]. Since the significant component of the human body is primarily made up of water, there is a high probability of radiation interacting with the water molecules and in the process cause radiolysis of water, which produces free radicals. The interaction of radiation with water leads to the breakage of bonds holding the water molecules together and thus producing fragments such as hydrogen and hydroxyls. These fragments are highly mobile due to unpaired electrons and can combine to form toxic substances [24]. Reports from experimental and clinical studies have revealed that kidneys are relatively more radiosensitive organs than other organs. The development of radiation-induced injuries sustain by the kidney may take months to years before manifesting [25]. Radiation-induced liver disease (RILD) is a dose-preventing intricacy of the liver exposed to radiation, and the therapy alternative for RILD is restricted [26]. Even in acute cases, it causes the liver's inability to carry out its metabolic functions, leading to death. Ingold et al. [27] reported the first description of radiation-induced liver disease as a significant complication associated with the liver's disease radiotherapy. Even though this disease's latent period takes 4-8 weeks post-radiation treatment, an investigation has revealed that the disease has a potency of manifesting as early as 2 weeks or as late as seven months
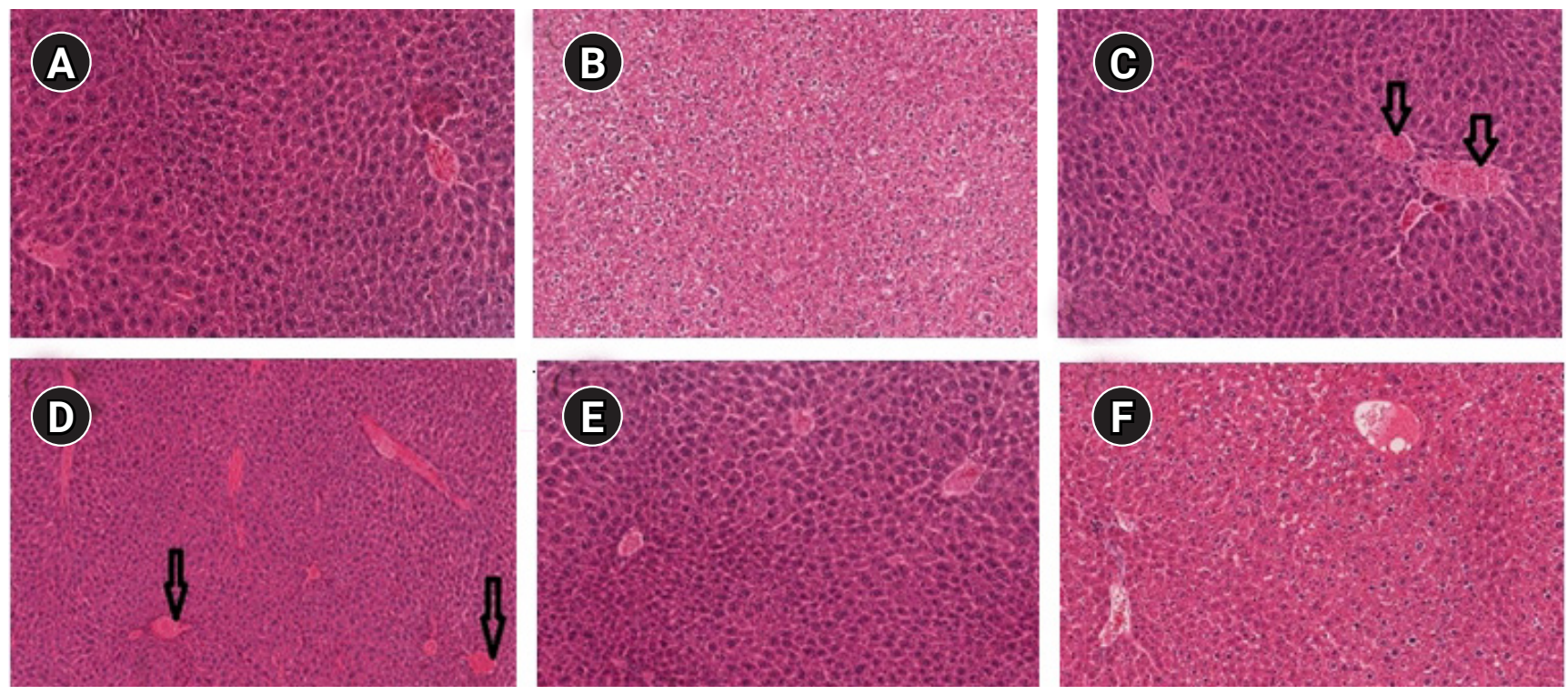

Fig. 2. Effects of Costus afer and X-ray radiation on the histological parameters of mice: the pathological analysis results of the liver. (A) Light micrograph of the liver section of the control mice, a normal hepatic architecture is evident with a normal ratio of portal triads and hepatic lobules $(H \& E, \times 400)$. (B) Light micrograph of the liver section of mice treated with $C A E$, no congestion is seen in the hepatic sinusoids (H\&E, $\times 400$ ). (C) Light micrograph of the liver section of mice exposed to $3 \mathrm{~Gy}$ of X-ray showing random foci of mild hepatocellular necrosis (arrows) $(H \& E, \times 400)$. (D) Light micrograph of the liver section of mice exposed to $6 \mathrm{~Gy}$ of X-ray showing random foci of mild hepatocellular necrosis (arrows) (H\&E, $\times 400)$. (E) Light micrograph of the liver section of mice treated with CAE \& exposed to 3 Gy of X-ray showing no visible lesion $(H \& E, \times 400)$. (F) Light micrograph of the liver section of mice treated with CAE \& exposed to 6 Gy of $X$-ray showing no visible lesion (H\&E, $\times 400)$. CNT, control; CAE, Costus afer extract; $H \& E$, hematoxylin and eosin staining. 
post-irradiation therapy $[28,29]$. Even though the clinical application of ionizing radiation in radiotherapy and other medical areas is widely accepted and has accrued colossal success, the damage to the healthy surrounding tissues has limited its usage. Thus, there is an urgent need to develop drugs from plants and herbs capable of scavenging free radicals, thus protecting the normal cells during radiotherapy and reducing radiation's harmful effect in an emergency radiation accident. This is the motivation for this work.

In the present study, we assessed Costus afer extract's ability in mitigating radiation-induced hematological and histopathological disorder in mice. The results showed that $\mathrm{X}$-ray radiation caused a significant alteration in the hematological parameters as evident in the degree of blood counts. Our findings revealed that 3 Gy and 6 Gy dose of $X$-ray radiation caused a substantial reduction in the $\mathrm{PCV}, \mathrm{Hb}, \mathrm{WBC}$, lymphocytes, and platelet counts compared with those in control (CNT) and extract only (CAE) groups. The pretreatment of mice with the extract of Costus afer improved the listed hematological variables with a significant increase in their mean values. The reduction in the named hematological variables among the irradiated groups is an indication that whole-body irradiation is mostly observed in the proliferating bone marrow progenitor cell. The decrease in the number of WBC and lymphocytes in the irradiated groups and the corresponding increase in the treatment groups are comparable to Shirazi et al. [26]. They reported that pretreatment with melatonin in rats $(10 \mathrm{mg} / \mathrm{kg})$ before exposure to 2 Gy and 8 Gy statistically increased the number of WBC and lymphocytes at 4-hour post-irradiation.

Moreover, gastrointestinal and haemopoietic cells in the bone marrow, which happen to be the most radiosensitive organs, are essential for maintaining life, and any injury to these cells can damage normal physiological activities [11]. The present study results concur with the findings of Gowda et al. [13], who reported that electron beam radiation caused a significant reduction in the $\mathrm{Hb}$, erythrocytes, leukocytes, PCV, and the platelet count 48-hour post-irradiation in male rats. Similarly, the results of the present study are consistent with the findings of Eshak and Osama [30], who showed a substantial decrease in WBC, RBC, PCV, Hb, and platelet exposure of $4 \mathrm{~Gy}$ and $6 \mathrm{~Gy}$ of gamma radiation to animals. In the present study, X-ray radiation caused a significant reduction in the mean of PCV and $\mathrm{Hb}$. Our result is also in total agreement with the findings of Udem and Ezeasor [31], who reported that Costus afer extract caused a significant reduction in the $\mathrm{Hb}, \mathrm{RBC}$, and PCV compared with the control group. A non-significant decrease in the mean of RBC was observed in the mice exposed to both radiation doses. This may be attributed to erythrocyte's relatively radioresistant nature compared with other blood's cellular components [4]. The observed decrease in the mean value of eryth- rocytes observed in this study might be due to mature $\mathrm{RBC}$ damage. In addition, it may be due to hemolysis and decreased erythrocyte production [32]. The present study revealed that the given radiation doses significantly lowered the number of neutrophils in the experimental animals; giving rise to a condition known as neutropenia. Neutrophils are mostly present in the WBC. The pretreatment of mice with the CAE partially ameliorated the damaged. WBC assist the body in fighting infectious and destroying harmful bacteria that spread into the body. Neutrophils are the most crucial protector present in the WBC that fights against infection. Report from literature revealed the radioprotective and antioxidant properties of Costus afer. For instance, the plant is used to cure ailments or conditions such as rheumatism, cough, hepatic disorders, miscarriages, hemorrhoids, inflammation, arthritis, helminthic, epileptic attack, as well as purgative, diuretics. It has also been tested as a cure for poison [33,34]. Okugbo and Oriakhi [35] reported that Costus afer could serve as free radical scavengers, acting perhaps as critical antioxidants, which could treat the disease that results from oxidative damage.

The inhibition of lipid peroxidation is another biomarker in determining the radioprotective property of the plant. The study conducted by Moody and Okwagbe [36] on plant stem extracts of Costus afer shows that the plant possesses potent antioxidants in vitro. The results obtained by Tonkiri et al. [17] show that Costus afer exhibits high antioxidant and free radical scavenging activities. The plant is a significant source of natural antioxidants, which may be of great value in hindering the progress of various oxidative stresses and modulation of drug-induced toxicity. The present study results correlate with the report of Abdelmageed Marzook et al. [37], who earlier worked on the radioprotective efficacy of Costus in protecting hematological parameters. They revealed that Costus speciosus offered protection on hematological parameters (RBC, hematocrit, WBC, and reticulocytes) against gamma radiation. The findings of Anyasor et al. [33] revealed that the aqueous fraction of leaves and stem bark of Costus afer exhibited a high degree of inhibition of lipid peroxidation. In another related development, Anyasor et al. [18] reported that Costus afer contained anti-oxidative properties, the plant could serve as bioactive, and antioxidants compounds for nutrition and therapeutic purposes. Other studies have shown that Costus afer possess antioxidant, anti-inflammatory, anti-cancer, hepatoprotective and could stimulate total lymphocytes proliferation $[33,38]$. Research has shown that free radicals can cause oxidative stress that can result in cellular and biological damage [39].

Moreover, antioxidants have shown to offer resistance against oxidative stress by scavenging free radicals. The report of Atere et al. [40] revealed that the antioxidant activity of Costus afer might 
be responsible for its medicinal potentials. Furthermore, their information deduced that polyphenols, flavonoids and other antioxidants compounds account for its ability to scavenge free radicals [40].

Kidneys are critical organs in the body that play basal functions in both health and disease conditions. Due to kidneys' relative radiosensitivity nature, the organs are prone to damage through radiation effects [41]. The exposure of kidneys to radiation during radiotherapy has raised serious concern over the practical applicability of ionizing radiation for therapeutic and diagnostic purposes. The degree of radiation damage on the kidney largely depends on the volume and dose of the incident radiation dose [25,42]. Reports in many clinical and experimental studies have shown that the liver is also one of the most commonly injured organs during radiotherapy for cancers of the abdominal region [43]. In the present investigation, whole-body exposure of mice to 3 Gy and 6 Gy radiation, the histological examination of the kidney revealed a few foci of mild cloudy swelling of the epithelial cells of tubules with a severe flattening of epithelial cells in the cortex-medullary junction. The administration of extract before irradiation showed no significant improvement in the histological examination of the kidney.

Similarly, the liver histology of the mice exposed to 3 Gy and 6 Gy radiation showed that there are random foci of mild single-cell hepatocellular necrosis, whereas, in the pretreatment groups (group CAE_3Gy and CAE_6Gy); hepatocytes seem to be within normal histological limits. This may be due to the time interval between irradiation and the harvesting of organs. Our findings contradict the findings of Tonkiri et al. [17] who reported Costus afer extract's protective ability and showed that the extract could act as a potent hepatoprotective agent against alcohol-induced liver cirrhosis. The contradiction in the results of the present investigation may be because a short time frame between exposure and harvesting of organs was observed. It could also be that the extract was administered over a few days, and lower radiation doses (3 Gy and $6 \mathrm{~Gy}$ ) were used, which were insignificant when compared with radiation dose tolerance of kidney and liver tissue. The 6 days administration of Costus afer adopted in the present study is negligible compared with the 6 weeks employed in the report of Tonkiri et al. [17]. The administration of the extract over a few days may be one factor for its non-significant effect in the histology analysis. However, the present findings correlate with Udem and Ezeasor [31] report, where the acute and subchronic toxicity of Costus afer was performed in mice. Their results showed no significant lesions in the kidney, liver, heart of the experimental, and control mice were recorded as revealed in the histopathological analysis. The report of their findings is in agreement with the result obtained from the present study. Similarly, the present study agrees with the report of
Ezejiofor et al. [44] on the activity of Costus afer against hyperglycemic induced hepatotoxic and histopathological changes; their report showed no histological changes in the harvested organs. However, the hematological analysis revealed that rats treated with the extract of Costus afer had a significant increase in WBC, RBC, $\mathrm{Hb}$, and platelet count compared with the control group. Ezejiofor et al. [44] also saw a significant increase in the lymphocyte level.

In conclusion, evidence from the present study indicates the possible potential of Costus afer to mitigate radiation-induced hematological alterations. Even though CAE's mechanism of action exerts its protective effect is unknown, it may be due to its ability to scavenge free radicals and reactive oxygen species. As reports from literature show, the plant exhibited antioxidant property, capable of neutralising the toxic peroxides and hydroxyl ions formed from the hydrolysis of water molecules after radiation exposure. The various compounds such as polyphenols, flavonoids and other antioxidants present in CAE may also protect hematopoietic cells in mice against radiation-induced damage, leading to increased blood counts in the hematological parameters. The histology examination revealed no visible lesion associated with irradiated and treated mice's kidney and liver. Further studies are warranted to validate the histopathology analysis; we propose varying parameters such as an increase in radiation dose, latent period and quantity (dose) of the extract can help authenticate the radiation-induced disorder to the histopathological parameters. The results of the hematology analysis from the present investigation support local claims of the therapeutic uses of Costus afer in the treatment of various kinds of ailments in folklore medicine; thus, Costus afer plant may be a potent radioprotector in the treatment of cancerous cells and for general use in case of a radiation emergency.

\section{Conflict of Interest}

No potential conflict of interest relevant to this article was reported.

\section{Acknowledgements}

The authors wish to express their sincere appreciation to the management and staff of the Department of Radiotherapy and Oncology, Grey's Hospital KwaZulu-Natal, South Africa, for providing the irradiation facility. Special thanks to Mr Mdletshe Nipho for helping in the radiation dosimetry and technical support. We also extend gratitude to Mr Ebrahim Ally of the School of Life Sciences, University of KwaZulu-Natal, Pietermaritzburg campus for assisting in the oral gavage and collection of blood samples.

This work is based on the research supported wholly to the first 
author by the National Research Foundation (NRF) of South Africa (No. 116089). The author acknowledges that opinions, findings and conclusions or recommendations expressed in this publication generated by the NRF-supported research are those of the author and that the NRF accepts no liability whatsoever in this regard.

\section{References}

1. Mishra KN, Moftah BA, Alsbeih GA. Appraisal of mechanisms of radioprotection and therapeutic approaches of radiation countermeasures. Biomed Pharmacother 2018;106:610-7.

2. Yamini K, Gopal V. Natural radioprotective agents against ionizing radiation: an overview. Int J Pharmtech Res 2010;2:1421-6.

3. International Atomic Energy Agency. Radiation biology: a handbook for teachers and students. Vienna, Austria: International Atomic Energy Agency; 2010.

4. Owoeye O, Onwuka SK, Farombi EO. Vernonia amygdalina leaf extract and alpha-tocopherol alleviated gamma radiation-induced haematological and biochemical changes in rats. Int J Biol Chem Sci 2011;5:1978-92.

5. Adaramoye 0, Ogungbenro B, Anyaegbu O, Fafunso M. Protective effects of extracts of Vernonia amygdalina, Hibiscus sabdariffa and vitamin $\mathrm{C}$ against radiation-induced liver damage in rats. J Radiat Res 2008;49:123-31.

6. Kuruba V, Gollapalli P. Natural radioprotectors and their impact on cancer drug discovery. Radiat Oncol J 2018;36:265-75.

7. Jagetia GC, Ganapathi NG, Venkatesh P, Rao N, Baliga MS. Evaluation of the radioprotective effect of Liv 52 in mice. Environ Mol Mutagen 2006;47:490-502.

8. Patt HM, Tyree EB, Straube RL, Smith DE. Cysteine protection against X irradiation. Science 1949;110:213-4.

9. C Jagetia G. Radioprotective potential of plants and herbs against the effects of ionizing radiation. J Clin Biochem Nutr 2007;40: 74-81.

10. Hall EJ, Giaccia AJ. Radiobiology for the radiologist. 7th ed. Philadelphia, PA: Lippincott Williams \& Wilkins; 2012.

11. Jagetia GC, Baliga MS. Evaluation of the radioprotective effect of the leaf extract of Syzygium cumini (Jamun) in mice exposed to a lethal dose of gamma-irradiation. Nahrung 2003;47:181-5.

12. Jagetia GC, Venkatesh P, Baliga MS. Evaluation of the radioprotective effect of Aegle marmelos (L.) Correa in cultured human peripheral blood lymphocytes exposed to different doses of gamma-radiation: a micronucleus study. Mutagenesis 2003;18:38793.

13. Gowda DK, Shetty L, Krishna AP, Kumari SN, Sanjeev G, Naveen P. The efficacy of nardostachys jatamansi against the radiation induced haematological damage in rats. J Clin Diagn Res 2013;7:
982-6.

14. Thimmaiah NM, Joshi CG, Patil RK, et al. Mitigation of radiation-induced oxidative stress by methanolic extract of Tragia involucrata in swiss albino mice. Pharmacognosy Res 2019;11:23643.

15. Targhi RG, Banaei A, Saba V. Radioprotective effect of grape seed extract against gamma irradiation in mouse bone marrow cells. J Cancer Res Ther 2019;15:512-6.

16. Sadeghi R, Razzaghdoust A, Bakhshandeh M, Nasirinezhad F, Mofid B. Nanocurcumin as a radioprotective agent against radiation-induced mortality in mice. Nanomed J 2019;6:43-9.

17. Tonkiri A, Essien ES, Akaninwor JO. Evaluation of hepatoprotective and in vivo antioxidant activity of the methanolic stem extract of Costus afer (bush cane) in alcohol induced liver cirrhosis in rats. J Biol Food Sci Res 2014;3:29-34.

18. Anyasor GN, Ogunwenmo O, Oyelana OA, Akpofunure BE. Phytochemical constituents and antioxidant activities of aqueous and methanol stem extracts of Costus afer Ker Gawl. (Costaceae). Afr J Biotechnol 2010;9:4880-4.

19. Soladoya MO, Oyesiku 00. Taxonomy of Nigerian medicinal plants. In: Odugbemi T, editor. A textbook of medicinal plants from Nigeria. Lagos, Nigeria: University of Lagos Press; 2008, p. 93-149.

20. Anaga AO, Njoku CJ, Ekejiuba ES, Esiaka MN, Asuzu IU. Investigations of the methanolic leaf extract of Costus afer. Ker for pharmacological activities in vitro and in vivo. Phytomedicine 2004;11:242-8.

21.National Institutes of Health. Guide for the care and use of laboratory animals (No. 85-23). Bethesda, MD: National Institutes of Health; 1985.

22. Organisation for Economic Cooperation and Development. OECD Guidelines for the testing chemicals, Section 4 (Testing No. 423: Acute oral toxicity - Acute toxic class method). Paris, France: Organisation for Economic Cooperation and Development; 2002.

23. Shastry CS, Aswathanarayana BJ, Ganesh S, Kalluraya B, Santanu S, Atanu B. Herbal radioprotector: re-emerging trend in the field of radio therapy. J Pharm Res 2012;5:2355-65.

24. Nair CK, Parida DK, Nomura T. Radioprotectors in radiotherapy. J Radiat Res 2001;42:21-37.

25. Kucuktulu E. Protective effect of melatonin against radiation induced nephrotoxicity in rats. Asian Pac J Cancer Prev 2012;13: 4101-5.

26. Shirazi A, Mihandoost E, Mohseni M, Ghazi-Khansari M, Rabie Mahdavi S. Radio-protective effects of melatonin against irradiation-induced oxidative damage in rat peripheral blood. Phys Med 2013;29:65-74.

27. Ingold JA, Reed GB, Kaplan HS, Bagshaw MA. Radiation hepatitis. Am J Roentgenol Radium Ther Nucl Med 1965;93:200-8.

28. Benson R, Madan R, Kilambi R, Chander S. Radiation induced liver 
disease: a clinical update. J Egypt Natl Canc Inst 2016;28:7-11.

29. Kim J, Jung Y. Radiation-induced liver disease: current understanding and future perspectives. Exp Mol Med 2017;49:e359.

30. Eshak MG, Osman HF. Role of Moringa oleifera leaves on biochemical and genetical alterations in irradiated male rats. Middle-East J Sci Res 2013;16:1303-15.

31. Udem SC, Ezeasor CK. The acute and subchronic toxicity studies of aqueous leaf and stem bark extract of Costus afer ker (Zingiberaceae) in mice. Comp Clin Path 2010;19:75-80.

32. Meyer DJ, Coles EH, Rich $\sqcup$. Veterinary laboratory medicine: interpretation and diagnosis. Philadelphia, PA: Saunders; 1992.

33. Anyasor GN, Onajobi FD, Osilesi O, Adebawo O. Proximate composition, mineral content and in vitro antioxidant activity of leaf and stem of Costus afer (Ginger lily). J Intercult Ethnopharmacol 2014;3:128-34.

34. Taiwo AO, Bolanle AA. The leaf essential oil of Costus afer KerGrawl from Nigeria. Flavour Fragr J 2003;18:309-11.

35. Okugbo T, Oriakhi K. A comparative study of in vitro antioxidant activity and phytochemical constituents of methanol extract of Aframomum melegueta and Costus afer leaves. Jordan J Biol Sci 2015;8:273-9.

36. Moody JO, Okwagbe KE. Topical anti-inflammatory activity of Costus afer. Niger J Nat Prod Med 2003;7:46-8.

37. Abdelmageed Marzook E, El-Bayoumy AS, Marzook FA. Preclinical evaluation of carnosine and Costus as hematological protec- tive agents against gamma radiation. J Radiat Res Appl Sci 2019; 12:304-10.

38. Omokhua GE. Medicinal and socio-cultural importance of Costus afer (Ker Grawl) in Nigeria. Afr Res Rev 2011;5:282-7.

39. Zukowski P, Maciejczyk M, Waszkiel D. Sources of free radicals and oxidative stress in the oral cavity. Arch Oral Biol 2018;92:817.

40. Atere TG, Akinloye OA, Ugbaja RN, Ojo DA, Dealtry G. In vitro antioxidant capacity and free radical scavenging evaluation of standardized extract of Costus afer leaf. Food Sci Hum Wellness 2018;7:266-72.

41. Ismail AF, Zaher NH, El-Hossary EM, El-Gazzar MG. Modulatory effects of new curcumin analogues on gamma-irradiation: induced nephrotoxicity in rats. Chem Biol Interact 2016;260:14153.

42. Brady LW, Halperin EC, Perez CA. Principles and practice of radiation oncology. 5th ed. Philadelphia, PA: Lippincott Williams \& Wilkins; 2008.

43. Hanedan Uslu G, Canyilmaz E, Serdar L, Ersoz S. Protective effects of genistein and melatonin on mouse liver injury induced by whole-body ionizing radiation. Mol Clin Oncol 2019;10:261-6.

44. Ezejiofor AN, Asomugha RN, Igweze Z. Protective effects of aqueous stem extract of Costus afer on hyperglycaemic induced hematotoxic and histopathological changes in Wistar albino rats. World J Pharm Pharm Sci 2017;6:162-78. 